\title{
Impact of Angiotensin II Receptor Blockers \\ on the Progression and Regression of Coronary Atherosclerosis
} An Intravascular Ultrasound Study

\author{
Katsuhisa Waseda, MDI; Yukio Ozaki, MD*,I; Hiroaki Takashima, MD; \\ Junya Ako, MD**; Tatsuya Yasukawa, MD ${ }^{\dagger}$; Tevfik F Ismail, MB BS, MRCP ${ }^{\dagger \dagger}$; \\ Hitoshi Hishida, MD*; Takayuki Ito, MD
}

\begin{abstract}
Background Although angiotensin II receptor blockers (ARB) have been found to reduce the coronary atherosclerotic plaque burden in animal models, it is unknown whether ARB have a similar effect on human coronary arteries.

Methods and Results Serial intravascular ultrasound (IVUS) studies of the left main (LM) coronary artery were performed in 64 patients at baseline and after 7-month follow-up. All patients were divided into 2 groups (ARB group: 23 patients; non-ARB group: 41 patients). Three-dimensional volumetric analysis was done throughout the LM coronary artery, and the volume index (VI; volume/length) was calculated for the vessel (VVI), lumen (LVI), and plaque (PVI). No significant difference was found between the 2 groups in baseline clinical characteristics, including age, gender, blood pressure levels, serum cholesterol levels, the presence of diabetes and smoking status. At baseline VVI, LVI and PVI were similar between the groups. In the non-ARB group, VVI, LVI, and PVI did not change between baseline and follow-up. In the ARB group, PVI significantly decreased during follow-up $\left(9.9 \pm 3.1 \mathrm{~mm}^{2}\right.$ vs $\left.9.1 \pm 2.7 \mathrm{~mm}^{2}, \mathrm{p}<0.01\right)$, whereas VVI and LVI were unaffected.

Conclusions This preliminary IVUS study suggests that ARB could cause regression of coronary atherosclerosis in humans. (Circ J 2006; 70: 1111-1115)
\end{abstract}

Key Words: Angiotensin II receptor blocker; Coronary artery disease; Intravascular ultrasound; Ischemic heart disease; Left main coronary artery; Plaque regression

$A$ ngiotensin II receptor blockers (ARB) have been shown to improve long-term outcome in patients with hypertension and left ventricular hypertrophy, and recent experimental studies in animal models suggest that ARB could prevent the progression of atherosclerosis and therefore lead to plaque regression!-6 $\mathrm{Al}-$ though Strawn et al found that ARB inhibited fatty-streak formation by protecting low-density lipoprotein (LDL) from oxidation and suppressing vascular monocyte activation in non-human primates? Johnstone et al demonstrated in an animal model that ARB reduce macrophage accumulation and plaque disruption and thereby attenuate the development of atherosclerosis? More recently, 6-month administration of ARB has been reported to reduce the intimal hyperplasia in monkeys with diet-induced hypercholesterolemia. ${ }^{4}$ However, the in vivo effects of ARB on

(Received January 30, 2006; revised manuscript received June 2, 2006; accepted June 16, 2006)

Department of Cardiology, Aichi Medical University, Nagakute, *Division of Cardiology, Fujita Health University, Toyoake, Japan, **Center for Research in Cardiovascular Interventions, Stanford University, California, USA, ${ }^{\dagger}$ Cardiology Division, Yasukawa Clinic, Nagoya, Japan and Department of Cardiology and Internal Medicine, Colchester General Hospital, Essex, UK

IThe first two authors contributed equally.

Mailing address: Yukio Ozaki, MD, Division of Cardiology, Fujita Health University, 1-98 Dengaku, Kutsukake, Toyoake 470-1192,

Japan._E-mail: ozakiyuk@fujita-hu.ac.jp human coronary atherosclerosis have not been previously studied.

Recently, von Birgelen et al clearly indicated that the chronological changes of plaque burden estimated by intravascular ultrasound (IVUS) were significantly correlated to cardiovascular events and hyperlipidemia?,8 To determine the impact of $\mathrm{ARB}$ on the progression and regression of human coronary atherosclerosis, we performed a serial IVUS examination of the left main (LM) coronary artery of 64 patients with ischemic heart disease (IHD).

\section{Methods}

Study Population and Inclusion Criteria

We analyzed serial IVUS studies of 64 LM coronary artery atherosclerotic plaques at baseline and after 7-month follow-up. Patients were examined at the Aichi Medical University Cardiac Catheterization Laboratory and the Fujita Health University Cardiac Catheterization Laboratory. The following inclusion criteria were used: (1) de novo and hemodynamically insignificant plaque in the LM coronary artery, (2) serial high-quality IVUS studies of the entire the LM coronary artery $\geq 6$ months apart, (3) same type of IVUS catheter used at percutaneous coronary intervention (PCI) and follow-up, (4) non-ostial plaque location in the left anterior descending (LAD) and circumflex coronary (LCX) arteries, (5) no calcium deposit interrupting quantitative vessel cross-sectional assessment, (6) no PCI 
Table 1 Baseline Clinical Characteristics

\begin{tabular}{lccc}
\hline \hline & Non-ARB & ARB & p value \\
\hline$N$ & 41 & 23 & \\
Age (years) & $61 \pm 11$ & $62 \pm 10$ & $N S$ \\
\% Male & 88 & 83 & $N S$ \\
Coronary risk factors (\%) & & & \\
$\quad$ Hyperlipidemia & 54 & 65 & $N S$ \\
$\quad$ Hypertension & 44 & 52 & $N S$ \\
$\quad$ Diabetes & 39 & 52 & $N S$ \\
$\quad$ Smoking & 27 & 35 & $N S$ \\
$\quad$ Familial history & 21 & 16 & $N S$ \\
Angina type (\%) & & & \\
$\quad$ Stable/unstable angina & $66 / 34$ & $74 / 26$ & $N S$ \\
Prior myocardial infarction (\%) & 39 & 35 & NS \\
Treated vessel by PCI (\%) & & & \\
$\quad$ LAD/LCX & $95 / 5$ & $86 / 14$ & NS \\
Follow-up duration (month) & $7.3 \pm 2.4$ & $7.5 \pm 2.9$ & NS
\end{tabular}

$A R B$, angiotensin II receptor blockers; PCI, percutaneous coronary intervention; LAD, left anterior descending coronary artery; LCX, left circumflex coronary artery.

Table 2 Chronological Changes in Blood Pressure and Serum Lipid Profiles

\begin{tabular}{lccc}
\hline \hline & Non-ARB & ARB & p value \\
\hline Blood pressure changes (mmHg) & & & \\
Systole at baseline & $141 \pm 18$ & $140 \pm 20$ & NS \\
Diastole at baseline & $77 \pm 13$ & $80 \pm 14$ & NS \\
Systole at follow-up & $135 \pm 16$ & $140 \pm 21$ & NS \\
Diastole at follow-up & $76 \pm 11$ & $80 \pm 11$ & NS \\
Serum lipid profiles (mg/dl) & & & \\
Total cholesterol at baseline & $187.7 \pm 31.8$ & $183.3 \pm 25.3$ & NS \\
Triglycerides at baseline & $160.2 \pm 105.3$ & $153.5 \pm 75.4$ & NS \\
HDL-C at baseline & $49.1 \pm 14.5$ & $42.5 \pm 10.6$ & NS \\
LDL-C at baseline & $126.4 \pm 34.1$ & $116.1 \pm 30.7$ & NS \\
Total cholesterol at follow-up & $180.0 \pm 22.7$ & $172.8 \pm 32.4$ & NS \\
Triglycerides at follow- $u$ p & $139.3 \pm 77.8$ & $162.0 \pm 77.5$ & NS \\
HDL-C at follow-up & $53.3 \pm 15.3$ & $50.5 \pm 9.1$ & NS \\
LDL-C at follow-up & $108.7 \pm 25.8$ & $101.1 \pm 22.2$ & NS
\end{tabular}

$A R B$, angiotensin II receptor blockers; $L D L-C$, low-density lipoprotein cholesterol; HDL-C, high-density lipoprotein cholesterol.

in the very proximal LAD or LCX, which could affect LM coronary artery plaque, (7) successful PCI for discrete lesions in the LAD or LCX. Nonostial plaque location in the LAD and LCX was defined as angiographic lumen diameter $<30 \%$ in the worst view and $<50 \%$ plaque burden. Patients who had had angiotensin converting enzyme (ACE) inhibitors or ARB were excluded because of the similarity of each drug's action. In the ARB group, all patients received losartan $25-50 \mathrm{mg}$ daily. This study was approved by the local ethics committees and all patients gave their written informed consent.

Following successful PCI, all patients were subsequently treated with a combination of $\beta$-blockers, calcium-channel blockers, or ARB at the physician's discretion. Patients were subsequently divided into 2 groups (ARB and nonARB).

\section{PCI and IVUS Procedures}

PCI was performed according to standard clinical practice using the trans-radial or trans-femoral approach, 10 IVUS examination (2.5Fr, 40-MHz, Boston Scientific, Fremont, CA, USA) was performed with intracoronary administration of isosorbide dinitrate after successful PCI and at 7-month follow-up!1-14 A motorized pull back device
Table 3 Medical Treatments During the Follow-up Period

\begin{tabular}{lrrc}
\hline \hline & Non-ARB & ARB & p value \\
\hline ACE inhibitor & $0 \%$ & $0 \%$ & NS \\
Calcium channel blocker & $85 \%$ & $39 \%$ & $<0.01$ \\
$\beta$-blocker & $15 \%$ & $26 \%$ & $N S$ \\
Aspirin & $100 \%$ & $100 \%$ & $N S$ \\
Statin & $51 \%$ & $52 \%$ & $N S$ \\
Oral hypoglycemic drug & $10 \%$ & $13 \%$ & NS \\
\hline
\end{tabular}

$A R B$, angiotensin II receptor blockers; ACE, angiotensin converting-enzyme.

$(0.5 \mathrm{~mm} / \mathrm{s})$ was used for IVUS data acquisition ${ }^{13,14}$ and all IVUS images were recorded on S-VHS videotape for subsequent off-line analysis.

\section{IVUS Measurements}

The serial IVUS analysis was performed at an independent core laboratory of Aichi Medical University by 2 experienced investigators who were unaware of the medical treatment groups. Cross-sectional luminal area (LA) was defined as the integrated area central to the intimal leading edge echo ${ }^{14-16}$ The total vessel cross-sectional area (VA) was defined as the area inside the interface between the plaque-media complex and adventitia (area inside the external elastic membrane) and plaque area was defined as VA-LA 14-16 We measured vessel volume and lumen volume using an algorithm based on Simpson's rule! ${ }^{15,17}$ Plaque volume was calculated as vessel volume minus lumen volume! ${ }^{7}$ von Birgelen et al reported that plaque progession and regression in the LM coronary artery were significantly related to serum cholesterol changes and clinical events, 7,8 so we estimated the plaque volume changes (delta PV) as an indicator of coronary atherosclerosis progression. Volumetric analysis throughout the LM coronary artery was performed with a Netra 3D IVUS system (ScImage, Los Altos, CA, USA) ${ }^{17}$ To obtain 2 identical analysis segments of the LM coronary artery at baseline and follow-up IVUS studies, we displayed the baseline and follow-up IVUS images side-by-side and used serial IVUS video sequences, together with information about the motorized pullback speed, the operator's recorded comments, and landmarks such as the presence of calcium deposits, side branches, plaque shape, and vascular and perivascular structures. Given that volume index (VI) was calculated as volume divided by the length of the vessel (VVI), lumen (LVI), and plaque (PVI), the VI is reported in $\mathrm{mm}^{2}\left(=\mathrm{mm}^{3} / \mathrm{mm}\right)$.

The reliability of the IVUS measurement system was quantified using a vessel phantom model as previously described14,18-20 In brief, the correlation between true phantom volume and IVUS volume measurements was 0.99 , the mean difference (accuracy) of the 2 volumes was $-2.23 \mathrm{~mm}^{3}$ in the $5-20 \mathrm{~mm}$ length phantom (average length $12.5 \mathrm{~mm}$ ); the accuracy of the VI (per $1 \mathrm{~mm}$ ) was $-0.17 \mathrm{~mm}^{2}$, and the standard deviation (precision) was $0.10 \mathrm{~mm}^{3}$ in the validation study.

\section{Statistic Analysis}

Data were analyzed using the SAS statistical software package (SAS Institute, Cary, NC, USA). All continuous values are expressed as mean $\pm \mathrm{SD}$. Differences in categorical variables between the non-ARB group and ARB group were assessed using the chi-square test. The unpaired t-test was used to assess differences in continuous variables between the 2 groups. Differences between baseline and 
Table 4 Serial Intracoronary Ultrasound Measurements

\begin{tabular}{|c|c|c|c|c|c|c|}
\hline & \multicolumn{3}{|c|}{ Non-ARB } & \multicolumn{3}{|c|}{$A R B$} \\
\hline & Baseline & Follow-up & $p$ value & Baseline & Follow-up & $p$ value \\
\hline$V V I\left(m^{2}\right)$ & $23.4 \pm 5.5$ & $23.5 \pm 5.7$ & $N S$ & $24.2 \pm 5.2$ & $24.1 \pm 5.0$ & $N S$ \\
\hline$L V I\left(m^{2}\right)$ & $14.4 \pm 4.4$ & $13.9 \pm 4.1$ & $N S$ & $14.3 \pm 4.3$ & $14.9 \pm 3.8$ & $N S$ \\
\hline$P V I\left(m^{2}\right)$ & $9.0 \pm 3.0$ & $9.6 \pm 3.6$ & $N S$ & $9.9 \pm 3.1$ & $9.1 \pm 2.7$ & $<0.01$ \\
\hline
\end{tabular}

$A R B$, angiotensin II receptor blockers; VVI, vessel volume index; LVI, lumen volume index; PVI, plaque volume index.

The volume index was calculated as volume divided by the length $\left(\mathrm{mm}^{3} / \mathrm{mm}=\mathrm{mm}^{2}\right)$.
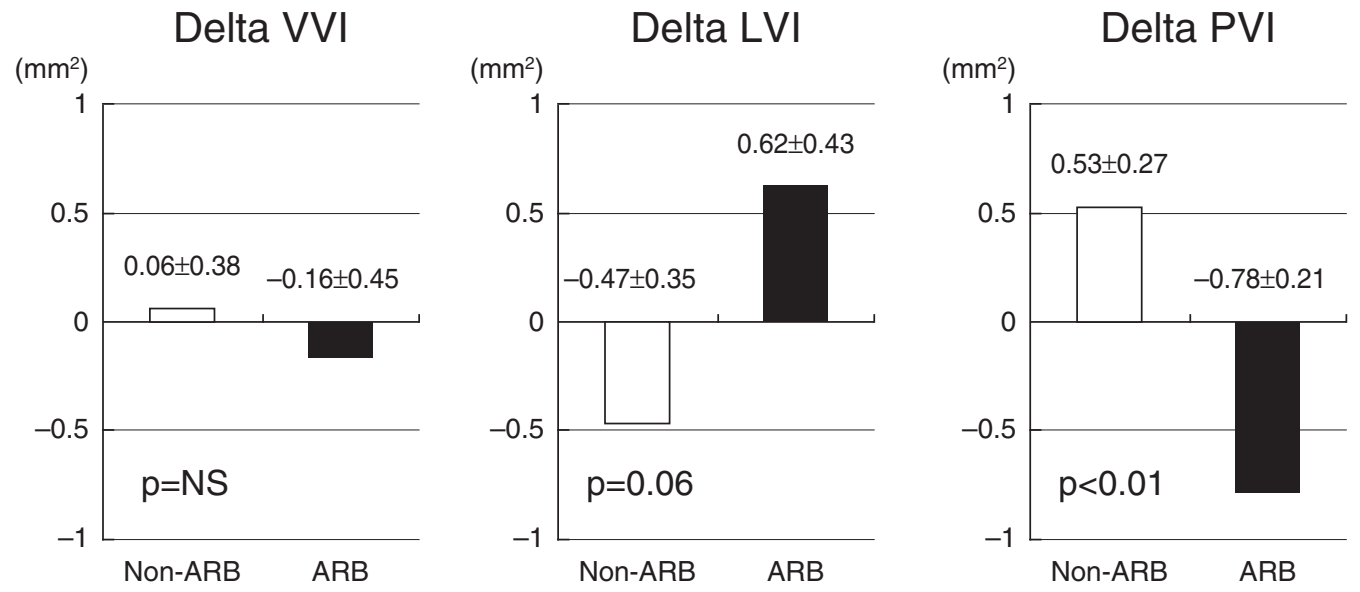

Fig 1. Delta VVI was similar between the non-ARB and ARB groups, but delta LVI tended to be greater in the ARB (average lumen gain) in comparison with the non-ARB (average lumen loss). Subsequently, delta PVI was significantly lower in the ARB group than that in the non-ARB group $(\mathrm{p}<0.01)$. The volume index (VI: volume/length) was calculated as volume divided by the length $\left(\mathrm{mm}^{3} / \mathrm{mm}=\mathrm{mm}^{2}\right)$ of the vessel (VVI), lumen (LVI), and plaque (PVI). ARB, angiotensin II receptor blocker.

follow-up were assessed with Student's paired t-test. A value of $\mathrm{p}<0.05$ was considered statistically significant.

\section{Results}

\section{Baseline Clinical Characteristics}

A total of 64 patients were enrolled in this observational study (non-ARB group: 41 patients; ARB group: 23 patients). No significant difference was observed in the baseline clinical characteristics of the 2 groups (Table 1). The follow-up duration was also similar (non-ARB: $7.3 \pm 2.5$ months; ARB: $7.5 \pm 3.0$ months, $\mathrm{p}=\mathrm{NS}$ ) (Table 1). There was no significant difference in blood pressure or serum lipid level between the 2 groups both at baseline and at follow-up (Table 2). Table 3 summarizes the medication status of the patients. None of the patients had had ACE inhibitors in accordance with the inclusion criteria of the study. In the ARB group, 10 patients had $25 \mathrm{mg}$ losartan daily and the remaining 13 received $50 \mathrm{mg}$ daily (mean dose $39.1 \pm 12.7 \mathrm{mg}$ ). The number of patients taking calciumchannel blockers was significantly greater in the non-ARB group than in the ARB group. Rates of use of $\beta$-blockers, aspirin, statins and oral hypoglycemic drugs were also similar between the 2 groups.

\section{IVUS Findings}

Volumetric IVUS analysis indicated no baseline differences between the non-ARB and ARB groups in VVI (nonARB $23.4 \pm 5.5 \mathrm{~mm}^{2}$ vs ARB $24.2 \pm 5.2 \mathrm{~mm}^{2}, \mathrm{p}=\mathrm{NS}$ ), LVI (non-ARB $14.4 \pm 4.4 \mathrm{~mm}^{2}$ vs ARB $14.3 \pm 4.3 \mathrm{~mm}^{2}, \mathrm{p}=\mathrm{NS}$ ) and PVI (non-ARB $9.0 \pm 3.0 \mathrm{~mm}^{2}$ vs ARB $9.9 \pm 3.1 \mathrm{~mm}^{2}$, $\mathrm{p}=\mathrm{NS}$ ). Whereas the non-ARB group did not show a signifi- cant chronological change in VVI, LVI, and PVI, the ARB group exhibited a significant decrease in PVI during follow-up (baseline $9.9 \pm 3.1 \mathrm{~mm}^{2}$ vs follow-up $9.1 \pm 2.7 \mathrm{~mm}^{2}$, $\mathrm{p}<0.01)$ (Table 4). The delta VVI was similar between the 2 groups, delta LVI tended to be greater in the ARB (lumen gain) in comparison with the non-ARB group (Fig 1). Subsequently, delta PVI was significantly lower in the ARB group than that in the non-ARB group (Fig 1).

\section{Discussion}

The results reveal that use of ARB may retard progression of atherosclerotic plaques and stimulate plaque regression in patients with IHD.

\section{Renin-Angiotensin-Aldosterone Axis and Progession of Coronary Atherosclerosis}

The renin-angiotensin-aldosterone axis plays a critical role in the pathogenesis of cardiovascular disease ${ }^{21}$ Angiotensin II stimulates intracellular pathways that promote atherosclerosis through inflammation, endothelial dysfunction, proliferation, fibrosis and thrombosis ${ }^{21-23}$ Animal studies have shown that inhibition of the renin-angiotensin system suppresses proliferation of smooth muscle cells and prevents atherosclerosis progression?,24,25 ARB inhibit the renin-angiotensin system more selectively than ACE inhibitors, therefore the administration of ARB could be a favorable strategy for preventing plaque progression.

\section{IVUS-Detected LM Coronary Artery Plaque Burden and Cardiovascular Event Risk}

Our IVUS findings suggest that the administration of 
ARB is associated with a reduction in coronary plaque burden during follow-up. Von Birgelen et al have recently reported the close relationship between adverse cardiac event-risk and plaque progression in the LM coronary artery measured by IVUS 7,8 Although it has already been shown that ARB improve long-term outcome in patients with hypertension and left ventricular hypertrophy, ARB that could improve plaque burden in the coronary artery would convey a more favorable long-term outcome in patients with coronary atherosclerosis!

Although randomized studies have demonstrated that ARB improves cardiovascular morbidity and mortality in patients with hypertension or heart failure and reduces cerebrovascular events in patients with cerebral ischemia or hypertension, several studies have failed to show an advantage to using these agents with regard to the prevention of myocardial infarction (MI) $1,26-28$ In the Study of Cognition and Prognosis in the Elderly (SCOPE), candesartan was associated with a non-significant but worrying trend towards an increase in MI, despite the 3.2-mmHg lower systolic blood pressure achieved relative to placebo ${ }^{29}$ Furthermore, the Losartan Intervention For Endpoint reduction in hypertension (LIFE) study did not reduce rates of MI despite lowering blood pressure $1.7 \mathrm{mmHg}$ more than the comparator atenolol! In the VALUE study, valsartan failed to prevent the occurrence of MI in comparison with amlodipine, although heart failure was more effectively suppressed by valsartan than by amlodipine 26 It has long been recognized that MI occasionally occurs in mildly to moderately stenosed vessels, where the most severe stenosis is less than $50 \%$, the so-called jump-up phenomenon 30 A possible explanation for this is that the underlying mechanism responsible for the occurrence of MI might differ substantially from that responsible for the progression of coronary atherosclerosis.

\section{Possible Role of ARB in the Progression and Regression of Coronary Atherosclerosis}

Strawn et al demonstrated for the first time an antiatherogenic effect of $\mathrm{ARB}$ in non-human primates. ARB (losartan) inhibited fatty-streak formation through mechanisms that may include protection of LDL from oxidation and suppression of vascular monocyte activation and recruitment factors? Johnstone et al recently found that ARB (candesartan) in a rabbit model reduced macrophage accumulation, increased collagen deposition within the plaque, reduced the frequency of plaque disruption and thereby attenuated the development of atherosclerosis? ARBs have been reported to decrease macrophage accumulation and chemokine expression, and attenuate LDL oxidation? 31,32 The doses of ARB used in those animal models were far greater than those used in clinical practice, raising doubts about whether the resultant findings can be directly extrapolated to humans. More recently, Takai et al reported for the first time that 6-month administration of ARB (olmesartan) in a monkey model reduced the carotid-artery intimal hyperplasia caused by 6-month high-cholesterol diet? Their experimental dose of ARB did not affect blood pressure or plasma cholesterol levels throughout the experimental study and nor did our dose alter either blood pressure or serum cholesterol levels during the follow-up period.

Despite such circumstantial evidence, it has not yet been established whether ARB can alter the process responsible for the progression of coronary atherosclerosis in humans. Our study lends support to the idea that ARB can retard the progression of atherosclerosis and facilitate plaque regression for the first time in humans with IHD.

\section{Study Limitations}

First, the number of patients undergoing serial volumetric IVUS analysis was small. A larger patient population with longer follow-up periods and serial IVUS studies is required to delineate the precise relationship between the administration of ARB, plaque progression and regression, and cardiovascular events. Second, the study was not randomized according to ARB or non-ARB arms, which raises the possibility of selection bias, although no special attention was paid concerning the selection of ARB or non-ARB arm during enrolment for the study. Finally, the administration of statins and the cholesterol level would affect progression of coronary atherosclerosis. Because no difference was found in the use of statins in the ARB and non-ARB groups (ARB 52\%, non-ARB 51\%), or in the cholesterol levels between the 2 groups (Table 2), it is theoretically assumed that statin and cholesterol levels contributed equally to the process of atherosclerosis in the 2 groups. In fact, no significant relationship was found between delta PV and total cholesterol level changes $(r=0.073, p=N S)$, delta PV and delta triglyceride $(\mathrm{r}=0.043, \mathrm{p}=\mathrm{NS})$, delta PV and delta high-density lipoprotein $(\mathrm{r}=0.091, \mathrm{p}=\mathrm{NS})$, and delta PV and delta LDL ( $\mathrm{r}=0.016, \mathrm{p}=\mathrm{NS})$.

\section{Conclusions}

This preliminary study indicates that long-term administration of ARB could contribute to the prevention of the progression of coronary atherosclerosis in patients with significant atherosclerotic disease. A long-term randomized follow-up study using ARB is needed to confirm the validity of these findings in a larger patient population with IHD.

\section{Acknowledgments}

We are grateful to all the staff of the catheterization laboratory, coronary care unit and cardiac wards at both Aichi Medical University Hospital and Fujita Health University Hospital for their dedication and contribution. We would like to thank Professor Itsuo Kodama, MD, PhD for his advice regarding the study.

\section{References}

1. Dahlof B, Devereux RB, Kjeldsen SE, Julius S, Beevers G, de Faire $\mathrm{U}$, et al. Cardiovascular morbidity and mortality in the Losartan Intervention For Endpoint reduction in hypertension study (LIFE): A randomized trial against atenolol. Lancet 2002; 359: 995-1003.

2. Strawn WB, Chappell MC, Dean RH, Kivlighn S, Ferrario CM. Inhibition of early atherogenesis by losartan in monkeys with dietinduced hypercholesterolemia. Circulation 2000; 101: 1586-1593.

3. Johnstone MT, Perez AS, Nasser I, Stewart R, Vaidya A, Al Ammary F, et al. Angiotensin receptor blockade with candesartan attenuates atherosclerosis, plaque disruption, and macrophage accumulation within the plaque in a rabbit model. Circulation 2004; 110: $2060-$ 2065.

4. Takai S, Jin D, Sakaguchi M, Muramatsu M, Miyazaki M. The regressive effect of an angiotensin II receptor blocker on formed fatty streaks in monkeys fed a high-cholesterol diet. J Hypertens 2005; 23: 1879-1886.

5. Daugherty A, Rateri DL, Lu H, Inagami T, Cassis LA. Hypercholesterolemia stimulates angiotensin peptide synthesis and contributes to atherosclerosis through the AT1A receptor. Circulation 2004; 110: 3849-3857.

6. Yamazaki T, Taniguchi I, Kurusu T, Shimazu Y, Hashizume Y, Takikawa K, et al. Effect of amlodipine on vascular responses after coronary stenting compared with an angiotensin-converting enzyme inhibitor. Circ J 2004; 68: 328-333.

7. von Birgelen C, Hartmann M, Mintz GS, Baumgart D, Schmermund A, Erbel R. Relation between progression and regression of athero- 
sclerotic left main coronary artery disease and serum cholesterol levels as assessed with serial long-term (>12 months) follow-up intravascular ultrasound. Circulation 2003; 108: 2757-2762.

8. von Birgelen C, Hartmann M, Mintz GS, van Houwelingen KG, Deppermann N, Schmermund A, et al. Relationship between cardiovascular risk as predicted by established risk scores versus plaque progression as measured by serial intravascular ultrasound in left main coronary arteries. Circulation 2004; 110: 1579-1585.

9. Ozaki Y, Keane D, Ruygrok P, van der Giessen WJ, de Feyter PJ, Serruys PW. Six-month clinical and angiographic outcome of the new less shortening Wallstent in native coronary arteries. Circulation 1996; 93: 2114-2120.

10. Ozaki Y, Serruys PW. Recent progress in interventional cardiology: Assessment by quantitative coronary angiography. Jpn Circ J 1997; 61: $1-13$.

11. Nakamura M, Wada M, Hara H, Kozuma K, Otsuka Y, Miyazaki S. Angiographic and clinical outcomes of a pharmacokinetic study of sirolimus-eluting stents: Lesson from restenosis cases. Circ J 2005; 69: $1196-1201$

12. Furukawa E, Hibi K, Kosuge M, Nakatogawa T, Toda N, Takamura $\mathrm{T}$, et al. Intravascular ultrasound predictors of side branch occlusion in bifurcation lesions after percutaneous coronary intervention. Circ $J$ 2005; 69: $325-330$.

13. Hong YJ, Jeong MH, Hyun DW, Hur SH, Kim KB, Kim W, et al. Impact of preinterventional arterial remodeling on in-stent neointimal hyperplasia and in-stent restenosis after coronary stent implantation. Circ J 2005; 69: 414-419.

14. Ozaki Y, Violaris AG, Kobayashi T, Keane D, Camenzind E, Di Mario C, et al. Comparison of coronary luminal quantification obtained from intracoronary ultrasound and both geometric and videodensitometric quantitative angiography before and after balloon angioplasty and directional atherectomy. Circulation 1997; 96: 491 499.

15. Matar FA, Mintz GS, Farb A, Douek P, Pichard AD, Kent KM, et al. The contribution of tissue removal to lumen improvement after directional coronary atherectomy. Am J Cardiol 1994; 74: 647-650.

16. Morino Y, Honda Y, Okura H, Oshima A, Hayase M, Bonneau HN, et al. An optimal diagnostic threshold for minimal stent area to predict target lesion revascularization following stent implantation in native coronary lesions. Am J Cardiol 2001; 88: 301-303.

17. Okazaki S, Yokoyama T, Miyauchi K, Shimada K, Kurata T, Sato H, et al. Early statin treatment in patients with acute coronary syndrome: Demonstration of the beneficial effect on atherosclerotic lesions by serial volumetric intravascular ultrasound analysis during half a year after coronary event: The ESTABLISH study. Circulation 2004; 110: 1061 - 1068

18. Shinjo H, Ozaki Y, Yasukwa T, Kakihana M, Waseda K, Kobayashi T. Role of three-dimensional intracoronary ultrasound (3D-IVUS) in coronary interventions: An experimental and clinical study. $J$ Aichi Med Univ Assoc 2002; 30: 15-23.

19. Ozaki Y, Keane D, Herrman JPR, Foley D, Haase J, den Boer A, et al. Coronary arteriography for quantitative analysis: An experimental and clinical comparison of cinefilm and video recordings. Am Heart
$J$ 1995; 129: $471-475$

20. von Birgelen C, Kutryk MJB, Gil R, Ozaki Y, Di Mario C, Roelandt JRTC, et al. Quantification of the minimal luminal cross-sectional area after coronary stenting: Two-dimensional and three-dimensional intravascular ultrasound versus edge detection and videodensitometry. Am J Cardiol 1996; 78: 520-525.

21. Weir MR, Dzau VJ. The renin-angiotensin-aldosterone system: A specific target for hypertension management. Am J Hypertens 1999; 12: $205 \mathrm{~S}-213 \mathrm{~S}$

22. Jacoby DS, Rader DJ. Renin-angiotensin system and atherothrombotic disease: From genes to treatment. Arch Intern Med 2003; 163: $1155-1164$

23. Singh BM, Mehta JL. Interactions between the renin-angiotensin system and dyslipidemia: Relevance in the therapy of hypertension and coronary heart disease. Arch Intern Med 2003; 163: 1296-1304.

24. Mueck AO, Seeger H, Lippert TH. Valsartan inhibits angiotensin IIstimulated proliferation of smooth muscle cells from human coronary artery. Int J Clin Pharmacol Ther 1999; 37: 365-366.

25. Wolf SC, Sauter G, Rodemann HP, Risler T, Brehm BR. Influence of growth factors on the proliferation of vascular smooth muscle cells isolated from subtotally-nephrectomized rats after endothelin or angiotensin II antagonism. Nephrol Dial Transplant 2005; 20: 312 318 .

26. Weber MA, Julius S, Kjeldsen SE, Brunner HR, Ekman S, Hansson $\mathrm{L}$, et al. Blood pressure dependent and independent effects of antihypertensive treatment on clinical events in the VALUE Trial. Lancet 2004; 363: 2049-2051.

27. Pfeffer MA, Swedberg K, Granger CB, Held P, McMurray JJ, Michelson EL, et al, CHARM Investigators and Committees. Effects of candesartan on mortality and morbidity in patients with chronic heart failure: The CHARM-Overall programme. Lancet 2003; 362: 759-766.

28. Schrader J, Luders S, Kulschewski A, Berger J, Zidek W, Treib J, et al, Acute Candesartan Cilexetil Therapy in Stroke Survivors Study Group. The ACCESS Study: Evaluation of Acute Candesartan Cilexetil Therapy in Stroke Survivors. Stroke 2003; 34: 1699-1703.

29. Lithell H, Hansson L, Skoog I, Elmfeldt D, Hofman A, Olofsson B, et al. The Study on Cognition and Prognosis in the Elderly (SCOPE): Principal results of a randomized double-blind intervention trial. $J$ Hypertens 2003; 21: 875-886.

30. Little WC, Constantinescu M, Applegate RJ, Kutcher MA, Burrows MT, Kahl FR, et al. Can coronary angiography predict the site of a subsequent myocardial infarction in patients with mild-to-moderate coronary artery disease? Circulation 1988; 78: 1157-1166.

31. Dol F, Martin G, Staels B, Mares AM, Cazaubon C, Nisato D, et al. Angiotensin AT1 receptor antagonist irbesartan decreases lesion size, chemokine expression, and macrophage accumulation in apolipoprotein E-deficient mice. J Cardiovasc Pharmacol 2001; 38: 395 405.

32. Rachmani R, Levi Z, Zadok BS, Ravid M. Losartan and lercanidipine attenuate low-density lipoprotein oxidation in patients with hypertension and type 2 diabetes mellitus: A randomized, prospective crossover study. Clin Pharmacol Ther 2002; 72: 302-307. 